\title{
Belfast Without Sight: Exploring Geographies of Blindness
}

\author{
Robert M. Kitchin \\ Department of Geography, National University of Ireland, Maynooth \\ R. Daniel Jacobson and Reginald G. Golledge \\ Department of Geography, University of California Santa Barbara
}

Mark Blades

Department of Psychology, University of Sheffield

\begin{abstract}
In this paper the transformed spaces of visually impaired and blind people is explored through a detailed analysis of interview transcripts with twenty seven visually impaired people living in or around Belfast. Data were collected using a structured open-ended interview and were analysed within NUD-IST, a qualitative data analysis package. Analysis revealed that visually impaired people become spatially confused (e.g. lost or disorientated) for two primary reasons. 'Self-produced' confusion is spatial confusion caused by the misperception/miscognition of a route (e.g. miscounting intersections). 'Situational' confusion is spatial confusion caused by a permanent or temporary localised occurrences such as road works, vehicles parked on pavements, and street furniture. Both types of spatial confusion were found to induce feelings of fear and anxiety, leading to a loss of selfconfidence, embarrassment and frustration, which in turn led to less independent travel and exploration, and constrained patterns of spatial behaviour. Respondents detailed a number of strategies for coping with spatial confusion. In addition, they assessed methods to make Belfast more navigable including environmental modifications and orientation and mobility aids.
\end{abstract}

Key Index Words: visual impairment, spatial behaviour, accessibility.

\section{Introduction}

Geographers have only recently started to turn their attention to issues of disability. Prior to 1990 there were only a handful of geographic studies which explicitly focused upon disability (Hall,1995). Since 1990 the number of empirical studies has grown significantly both in numbers and the range of issues addressed (see Park et al., 1998). This paper adds to the growing understanding of the geographies of disability through an examination of the daily experiences of people with severe visual impairments in negotiating the urban environments of Belfast and its surrounding towns.

Of all the sensory and physical impairments, severe visual impairment is probably the one that should receive the most attention from geographers. This is because vision is often quoted as the spatial sense par excellence (Foulke, 1983). Vision allows spatial information to be easily collected and processed, providing immediate perception of objects within an environment and allowing oneself to maintain orientation, to differentiate perspective and scale, and to locate objects in relation to one another and the perceiver (Brambring, 1982; Morrongiello et al., 1995; Sholl, 1996). It is generally thought that because people with visual impairments have to rely on other senses (tactile, proprioceptive and auditory) and modes of learning (sequential in nature) that their spatial knowledge is limited and their spatial behaviour restricted. Consequently, researchers such as Golledge (1993) have argued that the inability to travel independently and to interact with the wider

Irish Geography, Volume 31(1), 1998, 34-46. 
world is one of the most significant problems for people with visual impairment. Indeed, he suggests that people with severe visual impairments (and people with other impairments) occupy perceptually transformed spaces, that is, everyday geographic spaces whose meaning, form and function have been transformed (usually to a more complex, arduous to navigate through, and potentially hazardous, state) as a consequence of having an impairment:

While the space in which most people live is certainly not homogeneous, being replete with barriers and obstacles, and requiring effort to perform interactions, there is no doubt that this effort is magnified many times when one is disabled. For the disabled person the obstacles and barriers not only are multiplied, but are expanded well beyond the normal range; gutters become chasms, sidewalks and streets become treacherous paths, stairs may be impossible cliffs, distinctive sizes, shapes or colours may lose their significance, layouts may become a maze, maps and models may be uninterpretable. Space can become wildly distorted either through incomplete knowledge (for example, in the case of the blind or the retarded) or laboriously transformed (as in the case of the wheelchair user). (Golledge, 1993: 64 our emphasis)

Over the past few years a number of researchers have started to examine the geographies of blindness through four inter-related paths of research. The most developed of these paths concerns the measurement and assessment of people with visual impairments' ability to process, learn and store spatial information gained through both primary interaction and secondary sources (e.g. tactile maps) at the geographic scale (see Golledge et al., 1997 and Kitchin et al., 1997 for reviews). A second, highly related, path has sought to understand the basic spatial abilities (manipulation, transformation and rotation of objects and remembering layouts and navigating between places in a controlled laboratory) of people with severe visual impairment in order to determine the nature and extent of base-line, spatial mental processing (Klatzky et al., 1990; Loomis et al., 1993). The third path of study has examined the viability and success of different media in communicating spatial information. The mediums assessed include tactile maps (Ungar et al., 1994), tactile strip maps (Golledge, 1991), personal guidance system (Golledge et al., in press; Jacobson and Kitchin, in press), talking signs (Golledge et al., 1998; Jacobson, in press) and sound maps (Jacobson, in press). The fourth, and the least developed path, has explored the spatial experiences of people with severe visual impairments. For example, Cook (1991) provided a detailed ethnographic study of the spatial behaviour of four blind people in Effington, Kentucky. Butler and Bowlby (1997) investigated the attitudes of planners and able-bodied people towards blind people using public spaces through an examination of the experiences of their visually impaired respondents.

This paper seeks to add to the fourth path of research, exploring the main difficulties experienced by twenty seven visually impaired people in navigating through the Belfast urban environment, and detailing the suggestions they made which might make Belfast more navigable. The data analysed were collected via structured open-ended interviews as part of a wider project addressing issues of how people with severe visual impairments remember and learn routes through urban environments. The wider study compares the spatial behaviour of people in Northern Ireland and in the United States with little or no vision, investigating such issues as the effect of differences in mobility training, and the design of street layouts. The study reported here is currently being replicated in Santa Barbara, California.

\section{The Study}

\section{Respondents}

The participants in the part of the study reported here consisted of twelve people who were totally blind (no vision) and fifteen people who were visually impaired (legally blind but with some residual or peripheral vision). All respondents either lived in the Belfast urban area or within 15 miles $(24 \mathrm{~km})$ of Belfast city centre and were recruited through a variety of media: leaflet distribution through the Royal National Institute for the 
Blind and social work departments, a request for participation through an audio-magazine for visually impaired people in Northern Ireland, and snow-ball sampling from respondents already recruited. The totally blind respondents consisted of four females and eight males, were aged between 23 and 65 years ( $m e a n=41.0$, $\mathrm{sd}=11.1$ ) and had been blind between 2 and 38 years (mean=23.0, $\mathrm{sd}=10.5$ ). All were adventitiously blind. Six of the totally blind respondents were long cane users and six were guide dog users. The partially sighted respondents consisted of five females and ten males, were aged between 23 and 59 ( mean=37.5, $\mathrm{sd}=10.2$ ), and had been partially sighted between 1 and 42 years (mean=22.3, sd=16.1). Of the partially sighted respondents, two were guide dogs users, three used improvised mobility aids such as umbrellas and sticks to aid navigation, and the remainder used their residual vision to navigate. The orientation and mobility $(O$ and $M)$ training of the blind and partially sighted respondents varied considerably. The majority of participants had received orientation and mobility training shortly after becoming visually impaired, involving rehabilitation, guide dog or cane training and the learning of routes to places of relevance in their daily lives. However, three congenitally, partially sighted individuals had received no $\mathrm{O}$ and $\mathrm{M}$ training. All the data were collected between $12^{\text {th }}$ May and $28^{\text {th }}$ Oct 1997 . Respondents were paid $£ 10$.

\section{Methodology}

Each respondent was interviewed separately in his/her home by one of the authors (Jacobson) using a structured open-ended interview as part of a larger questionnaire. Within this interview style the conversation is highly controlled by the interviewer. Like closed quantitative questions as used on questionnaires, the questions are highly structured and standardised, but in contrast are open-ended in nature. This means that interviewee responses are not constrained to certain categories as provided by the interviewer but consist of whatever answer they wish to give (Patton, 1990). By using such a strategy it is expected that the open-ended questions will provide replies that better reflect a person's own thinking. In contrast to a more informal conversational strategy where there is no set agenda or questions (see Kitchin and Tate, in press), all the respondents are asked the same basic questions in the same order. The exact wording and sequence of the questions is determined before any of the interviews are conducted. This structured strategy was a way of increasing the comparability of responses and ensure responses to all questions for every interviewee. This strategy was used to reduce interviewer effects and biases introduced through free conversation. Furthermore, this structured approach provides a 'natural' basis of organisation for analysis of data. However, it is appreciated that this strategy does also have its weaknesses. On the one hand, because the interview is so highly structured and standardised it allows little flexibility in relating the interviews to particular individuals or circumstances (it removes individuality) and may also constrain and limit the 'naturalness' and relevance of questions and answers. On the other hand, respondent answers were not constrained to certain choices, meaning that although they may have experienced a certain situation it was not necessarily recorded.

\section{Analysis}

The interview data were transcribed, typed into plain ASCII files and imported and analysed using NUDIST 3.0.4 (Non-numerical Unstructured Data Indexing Searching and Theorising). NUD-IST allows qualitative data to be easily managed, cross-referenced, and analysed using simple Boolean operations to identify patterns. Using NUD-IST the data were analysed using the prescription detailed in Dey (1993) and Kitchin and Tate (forthcoming). This prescription is highly structured and rigorous consisting of three primary stages: description; classification; connection; that are operationalised through a sequence of standardised tasks. First, the data were transcribed. Each discrete passage was then annotated, detailing potential category allocation. Next, the data were sorted into categories of related material. Where relevant, data were assigned to more than one category. To aid the process of connection the data categories were then split (divided into new discrete categories) or spliced (merged to form new more generalised categories) to create new sorted categories of related data. Where appropriate, links between sorted categories of data were then examined 
using the Boolean operations within NUD-IST. Finally, the interpretations drawn from the data within each sorted category were corroborated in relation to evidence within other sorted categories.

This process of analysis means that it was possible to explore the richness of responses in a constructive and rigorous manner. In order to allow the data to 'speak for itself', so as to illustrate the sorts of problems and associated emotions encountered by visually impaired people as they navigate through an environment, and what they see as potential solutions, the following text is generously adorned with passages from relevant sorted categories. All respondent, and some place, names have been changed or omitted to preserve anonymity. The specific numbers of respondents citing a condition have not been provided because the part of the overall study reported here did not consist of a systematic checklist of the potential hazards encountered, coping strategies employed, or potential solutions. Instead, the data were collected to provide contextual information for stages two and three of the project. As such, although a respondent did not mention a particular hazard in the course of the interview it does not mean that they have not encountered such a situation in the past. Although a more systematic study is needed, the results still have merit in that they provide an initial insight into the spatial worlds of visually impaired people and highlight the sorts of issues a more systematic study should address.

\section{Spatial Confusion}

Even prior to analysing the transcripts it was evident from the interviews that people with visual impairments do live within transformed spaces: all detailed problems encountered when navigating through an urban environment that would not have affected their travel if they had been sighted. This is not to deny that many of the respondents successfully, and in the main independently, travelled around Belfast during the course of their daily lives, rather it acknowledges that every one of them expressed anecdotes that illustrated the transformed nature of urban space and the difficulties encountered when traversing alone an urban space without sight. Upon detailed analysis of the interview transcripts it became clear that the problems encountered and the spatial confusion these induced (e.g. lost, disorientation) could be divided into two distinct types. 'Self-produced' confusion is spatial confusion caused through the actions or misperception/ miscognition of the visually impaired person as they navigate a route. Examples include attempting shortcuts and miscounting choice points. In these cases, the visually impaired person is directly responsible for their spatial confusion. It should be noted that 'self-produced' confusion is by no means limited to visually impaired people, many people become lost or disorientated when they travel, but that it may be more prone in visually impaired people given the importance of sight in aiding navigation. In many cases, a person with a visual impairment's predicament may be compounded by 'situational' confusion. 'Situational' confusion is spatial confusion caused by a localised occurrence that may be permanent or temporary in nature. Here, confusion concerning location, orientation, and the route to be taken, is caused by specific features and occurrences in the environment. Examples include roadworks, vehicles parked on the pavement, and street furniture, which all disrupt the paths taken by visually impaired people and require spatial actions to avoid obstacles.

\section{'Self-produced' Confusion}

It is clear from the transcripts that 'self-produced' confusion arises due to two main reasons. In the first case, confusion arises because the visually impaired person used their spatial knowledge inaccurately. Examples include miscounting the number of intersections:

Res A: I got lost once. It tends to knock you sideways a bit. I crossed one too many streets and I ended up going in the opposite direction;

or attempting a short-cut through an area that the respondent feels they know well: 
Res S: I tried that [shortcutting] once, I had to go to a shopping centre and I cut through and I got completely lost. I was imagining where Sandy Row would be, and I walked down this street, but I ended up miles away by the Laganside.

In the second case, confusion arises because of incomplete knowledge. For example, the spatial layout of an area known well might have been altered but the spatial knowledge of the individual has not been updated:

Res A: I hadn't been down in the town for a while, but I knew there was work done on this part of the road. I didn't realise the Westlink went under the Falls Road. Nobody had ever told me that. I was walking across towards Divis Street, and suddenly I heard the roaring of a heavy thundering truck. 'Shit, this one's going to get me', I thought. Then it went underneath and I was $O K$.

In one case, a respondent reported that she consistently produced the same 'self-produced' confusion by miscounting the number of intersections:

Res $G$ : When we first moved here my son went to primary school with a friend's child. I took him to school every day for weeks and I would get him to school without fail. But as I came back on my own I would perpetually take the wrong turning. I think it was the one before I should have done - I would always end up in the same place.

\section{'Situational' Confusion}

The transcripts revealed that 'situational' confusion arose due to a number of different reasons. Principal amongst these reasons was pavement clutter which blocked paths, created obstacles, and in some cases could be considered health hazards. This clutter ranged from permanent street furniture such as bollards and benches, to semi-permanent shop-related items such as outdoor stands and signs, to transient features such as skips, wheelie-bins and vehicles parked on the pavement, as the following statements illustrate:

Res B: A lot of shops now have huge amounts of pavement clutter ... if it is bright and there are lots of people then I will bump into things.

Res $K$ : The cane is good, but there a things that it can't detect like head high signs and skips which can do a lot of damage.

Res $O$ : Here the streets are really narrow, and so are the footpaths are too. But they still have steps onto the pavement, jutting out, so it actually narrows the footpath in half again. There are also an awful lot of obstacles... When they put trees in and take a tile out of the pavement it becomes a problem for me. They have flower boxes hanging off walls too, at head height, at body height.

Res H: Prams and bicycles can be a real problem ... cars parked on pavements are a nuisance.

Res N: The cane doesn't detect overhangs. Last November a truck was parked at the side of the road. I came underneath it and whacked into the tailgate. I broke my nose and had 2 black eyes.

Res W: Thursday morning is the best, because that is bin day. All the bins are all over the place: the pavement; the street; half in driveways. With the cane this was a real problem, but now with my dog, he just leads me straight through, weaving as we need to.

Other shop related problems concern the design of the shop entrance and the spatial behaviour some environments induce in other shoppers:

Res C: Some places in the shopping centres you have to go up and grope the shop front looking for the door: You don't know if it is a window or a door: 
Res I: I try and avoid Castle Court [covered mall], everybody in it is all over the place [as opposed to ordinary shopping streets where people tend to walk in parallel lines along the pavement].

Another important reason for 'situational' confusion was road works which not only created the need to find an alternative path but often masked the locational sound clues used by some respondents to aid wayfinding:

Res D: I was on the Antrim Road, lines of shops, traffic and there was CableTel digging holes. There were pneumatic drills going, it was really disorientating - I couldn't use the traffic noise to work out which way I was facing.

Res B: I would get off the bus at the appropriate stop to find that the road had been dug up. The noise of the men working lets me know that they are working, but it is then off-putting as you can't find other sound clues to get around that.

Res E: CableTel were everywhere. Oh my God, I fell down more holes, you know... It didn't seem to be planned, like random blobs of work all over the streets. They don't take people with sight problems into consideration.

Crossing the road can be a particular problem because in some cases there is not a nearby pedestrian crossing and in other cases where a crossing exists it is not designed to aid people with visual impairments to cross:

Res J: The only thing is, sometimes there isn't that facility [pelican crossing], and there isn't a bleeper because of traffic management or whatever. ... I find it frustrating. Half of me thinks the motorist is probably waving me across, but then I can't see him, so he's probably getting frustrated.

Res Z: Other hazards include, crossings with bleepers, where they have been vandalised or broken and I can't see whether the lights have changed.

The problems of the siting and number of crossings was illustrated when walking routes with respondents. Some respondents would have to take long circuitous routes to get between places that were geographically near in order to use a crossing. For example, one respondent wanting to get from one side of the road to the other had to walk a quarter of a mile up one side of a street to a crossing and then walk back down the other side.

In some cases, specific spatial layouts caused confusion, with the visually impaired person unable to locate or orientate himself/herself within the layout:

Res B: I went to Westport for the day. ... It was built on a square, but I never knew what section of the square I was at. I could have been three quarters of the way around, when I needed to only go back a quarter, but I would go around. There was a river and a bridge and everyone seemed to go by these, but they didn't mean anything to me. It was frustrating and I was quite disorientated.

The use of public transport, upon which visually impaired people are predominantly reliant upon for independent travel, can create other problems. In some cases these are caused by an inability to identify the destination of the transport:

Res C: A few times I ve been, not lost, but mislaid. Recently, when I was on a course I got the wrong bus one morning. There were two buses leaving Lisburn, one was an express to the back of the city 
hall in Belfast and the other one went to ... somewhere. I soon knew the bus I was on wasn't going to the right place and I started sort of panicking, and then it was more really of a mental panic, 'I' $m$ in deep shit'.

and in other cases it is keeping track of where the transport is along its route:

Res G: If I am on a train or a bus and it is a journey I've not done very often, I can be very anxious because it is travelling so quickly that until we get to the stops I can t possibly know where I am.... I have to concentrate really hard.

One particular problem experienced in Belfast is caused by dropped kerbs installed by the City Council to facilitate access for wheelchair users. Here, the pavement becomes flush with the road, and in the absence of a tactile pavement, provides visual impaired people with no feedback about where the pavements end and the road starts:

Res A: There is a conflict between dropped kerbs and flush pavements. I can't tell a difference. If you go from Castle Street from Castle Court the place where the pavement should be, it just isn't there.

There is nothing to tell you where it is, it is all flush.

Indeed, the route learnt on the second part of the study contained a number of dropped kerbs and, several times, visually impaired people were witnessed walking straight out into the road when their cane failed to identify the boundary.

\section{Feelings Induced by Spatial Confusion}

As some of the above quotes illustrate, spatial confusion induces a number of negative feelings in people. Principal amongst these are feelings of fear, panic, anxiety and wariness. Indeed, other studies have indicated that many blind people only adhere to familiar, known routes, as exploration can be stressful, disorientating and create anxiety (Passini et al., 1990). This fear and anxiety manifests itself in constrained patterns of spatial behaviour. For example, Bruce et al. (1991) found in a survey of young, blind people in the UK that in the preceding week that 20 percent of respondents had not left their home, 34 percent had travelled locally, and only 41 percent had left the confines of the home alone and on foot. Similarly, Clark-Carter et al. (1986) reported that at least 30 percent of people with severe visual impairments make no independent journeys outside their homes.

Related to fear and anxiety are feelings of self-confidence, embarrassment and frustration. Nearly half of the respondents indicated that they suffered from low levels of confidence in their ability to travel independently, and were self-conscious of their actions and the opinions of other travellers, which inhibited their spatial behaviour:

Res N: The most frustrating thing is that I don't really have the confidence to go outside an area that I am familiar with. That is my own feeling - I am limited to the places I know.

Res C: When I do go into shops everything just brights out for a moment. So you stand there and look like a wally, everybody looking at you.

Res U: Certainly there is a feeling of panic - anxiety to be honest. In that situation [being lost] I would retrace my steps. If this didn't work I would ask people, if I was looking for somewhere specific. I think I would be too embarrassed to confess to people that I was lost, though if it came to it I would. 
Some respondents had been verbally criticised and abused for mishaps such as bumping into street furniture and asking for help when traversing a route. As a consequence, some of the respondents did not use their cane to aid navigation for fear of identifying themselves. Indeed Res E explained that the white cane can be a double-edged sword - when used it leads to unwanted help and when not used it leads to ridicule:

Res E: Maybe that is hard to explain. With a white cane everybody is always grabbing you by the arm and leading you across the road, whether you want to cross or not. When you ask for the way and you don't have a white cane, people tend to treat you as if you are stupid - what's the matter, it's just over there, can't you see it?

As a result, Res $\mathrm{O}$ relied on another cue, using an umbrella as a cane stating:

Res $O:$ I don't carry the stick because I'm self conscious.

Res B nicely intertwined these different themes when she discussed being lost:

Res B: I don't like it [being lost]. I hate being "out of control". It is not a good feeling. It can be an anxious feeling. It's also quite a confidence downer. All of a sudden you are not where you think you are and you feel a bit stupid. You think any other adult could manage this and maybe you can't so you feel inadequate in some way. How I would resolve it would be to ask somebody. It has, believe it or not, taken me nearly ** years to reach the point where I can ask somebody. You get a whole range of answers that you need emotional strength for; like the 'are you blind?' question.

\section{Coping With Transformed Geographies}

To deal with the transformed geographies of 'self-produced' and 'situational' confusion, and to try and minimise feelings of panic and anxiety and to maximise their confidence, all respondents resorted to a range of coping strategies. In nearly all cases the predominant strategies were to restrict independent travel to half-adozen or less, well known, familiar routes and to travel with a companion when negotiating other routes. However, when the first strategy failed, or a form of temporary 'situational' confusion was introduced (e.g. road works), or if a companion was not available and the route was still attempted, then other strategies were adopted. By far the most common of the secondary strategies was to ask people:

Res K: I would ask a passerby 'excuse me? Could you please tell me where I am?' Then I can get my bearings and try to rectify it from there. I would try to get back on route as quickly as possible... It is always easier to ask.

However, most respondents were reluctant to ask for help, initially preferring to try and find a solution to their dilemma, only resorting to asking when their other strategies failed. For example, some respondents would backtrack to take up an alternative route or, if confident, seek to find an alternative path around the obstacle:

Res $K$ : As I came across it, say the road being dug up, I would ask them how far it extended. Then I would try to work out what the shortcuts would be. As long as you know where you are going you are OK. If I was to go down A, B and C it will put me back on the route, and then I am happy enough. First left, first right, next right or whatever:

Res W: It would depend on what way I had to go. I can usually work out where I need to go, to go parallel on another street.

The reluctance to ask for help was, in the main, an attempt to retain independence, maintain pride and confidence, and minimise embarrassment. As Res O describes: 
Res $O$ : Last year on holiday in a caravan park I was lost and I got pretty angry with it. I had to ask for assistance from one of the wardens. I just couldn't find my way back to the caravan. That was the last time I was lost. It made me angry and frustrated. I didn't mind asking for help, but it annoyed me that I got to the stage and had to ask for help.

The next most popular strategy, particularly in the case of 'self-produced' confusion, was to retrace, backtracking along a route until a familiar place was located:

Res J: I would go back to where I started and then start again. I have to retrace to go back to where I know.

Respondents also employed a number of less-used strategies. For example, three of the partially sighted respondents described using a strategy of shadowing; using their residual vision to follow other pedestrians. As Res B describes:

Res B: I would, perhaps, if in town try to follow the flow of people, use them as guides even though they don't know it. The same is true for crossing roads. Rather than asking each time, I would find somebody who I think is reasonably competent and then follow them.

Guide dog users, in the case of 'situational' confusion, would resort to their Orientation and Mobility (O and $\mathrm{M}$ ) training to re-orientate themselves before taking a course of action. For example, in the following section of transcript, Res D describes how he re-orientated himself by following standard $\mathrm{O}$ and $\mathrm{M}$ training before back-tracking to take an alternative route:

Res D: There were pneumatic drills going, it was really disorientating - I couldn't use the traffic noise to work out which way I was facing. So I turned, took the dog to the kerb to reorientate myself, turned back and walked through the parallel streets that I know.

In a few cases, respondents expressed that they relied on the guidance of family and friends when travelling, only independently traversing a couple of well known routes:

Res C: If Gemma is there it is a lot easier, picking out the gaps in the wall, or going into shops.... Generally Gemma, my partner, would be with me. If it was left to me I would be in for a lot of trouble.

In general, however, it should be stressed that there was a high degree of independence amongst the respondents, most of whom were happy to travel on their own, as long as the route was well known. The need for familiarity meant though that the number of routes each respondent travelled was small, with few respondents willing to attempt shortcuts, take detours, or attempt routes for the first time unaided. As a consequence, patterns of unaccompanied spatial behaviour were constrained to just a handful of routes. In addition, due to the difficulties of learning a new route most respondents only learnt a new route occasionally and only if it was going to be used regularly:

Res I: [I] very rarely [learn a new route], I more or less know everywhere I go. ... The only time I go anywhere unfamiliar is when we're away on holiday, once a year:

Res L: I Rare[ly learn a new route], unless there is a special purpose like going to the hospital. I don't really go to strange places unless there is a purpose.

\section{Making Belfast Navigable}

In addition to asking respondents about their everyday experiences of navigating through the urban environment, they were also asked about what improvements needed to be made in relation to the planning and use of urban spaces, and discussed the potential benefits of possible navigation aids. 


\section{Changing Environments}

From analysis, it was clear that the environmental improvements that respondents suggested were more aimed at reducing 'situational' confusion than 'self-produced' confusion. In other words, respondents wanted to see changes to the urban fabric through which they navigated that would make their journeys less fraught with difficulties and potential hazards. In the main this consists of simple, low cost alterations, such as minimising the amount of street furniture. For example, respondents suggested:

Res B: Very simple practical ideas are needed, such as larger signs and painting the edges of all steps.

Res J: Larger signs are needed. Street signs in most towns are either too high or too low to read.

Res F: They should paint the kerbs, that would help. Sometimes I fall off even with the cane. I've been knocked down twice ... Drivers don't realise even if you have a cane. They don't really care. It scared me a bit last time, I just lost the edge of the kerb.

Res S: Painting a shop doorway would be good, like a yellow line by the door. I'm always walking into shop fronts looking for the door.

Res Z: As regards steps and things like that, I think either a white or a yellow line on the step corner would be ideal, to indicate the end of each step. Maybe, a couple of bands on a bus stop, say white for a lamp post and red or blue for a bus stop.

Res Y: Certainly a white line on the edge of steps is worth its weight in gold. Buses could do with an awful lot of wising up with their indicators - the signs. They are not reliable. You can't depend that the bus number actually will match the bus. The numbers are not big enough. They have also got to the stage where in about a two or three feet distance they are trying to fit 'Belfast City Centre' or 'Belfast Europa Bus Station'. You don 't have a hope, that has always been a problem.

Res I: mov[e] lamp posts to one side of the pavement.

Res X: People need to cut overhead branches, so you don't walk into those. Street furniture, I mean outside shops or display things, this needs to be tidied up.

Furthermore, respondents indicated that there needs to be consistency in all the structural modifications and additions to the urban fabric that are undertaken. For example,

Res D: Tactile pavements need to be standardised and there needs to be more of them.

Res $M$ : We need consistency, they are not uniform. You can spot a white line on one set of steps and then take a tumble on the next. Positioning of signs needs to be better:

Res $N$ : We need consistency in tactile markings at crossings and road junctions. They are good in some areas but they don't always end up at the pole with the button. ... If there was consistency it would really improve my confidence no end. Some go from the edge of the pavement to the inner shoreline, others just jut out into the path, so sometimes you can miss them.

Res W: Painting the edges of kerbs is a good idea, and the tactile stuff. In some streets the lamp posts are at the edge of the kerb, on others they are on the inside - there seems to be no logic. More standardisation or order would be good. 


\section{Overcoming Environments}

In contrast, it was generally felt that improved navigational aids would help reduce 'self-produced' confusion and open-up possibilities of widespread independent travel. A number of different aids were discussed. Respondents generally thought that tactile maps were a good idea.

Res N: Oh yes, these would be very useful, and they would be fun too. There are parts around here I don't know too well, a map of Lisburn would be really great.

There were reservations:

Res B: I imagine for me to pick out the map, the map would have to be quite large because I don't read Braille, so my fingers won't be as sensitive as someone who does.

Res H: I would be more keen on practical experience in the environment than to use my memory of a map.

Res Z: I have come across them before but I don't really find them very useful. I've found translating the map against where I wanted to go is difficult.

Similarly, it was regarded that both talking signs and audio guides would be useful aids to navigation:

Res Y: I've used those, in Disneyland. They were brilliant. Brilliant as much from the point of view that the information is good. In terms of getting around though it was hectic-millions of people in a relatively short space of area. I would equally say that anybody sighted would find these really useful too. The tapes are good;

although some respondents were concerned that they might interfere with using aural locational cues:

Res T: I think they would distract me. I like to be able to hear everything that is going on around me.

The greatest enthusiasm was reserved for personal guidance systems (combines global positioning system technology with a geographic information system (GIS) to provide a system which monitors on-theground location and provides verbal route directions between any of the places located within the GIS) which many respondents felt might open-up possibilities of independent travel.

Res E: This would be very useful in places you weren't familiar with. It would let people explore. A good move towards independence.

Res K: This would be the ultimate - I could explore. It would open up the world. I wouldn't be limited by my routes or by my limitations. It would be incredible.

However, not all respondents were overly keen. For example, Res R stated that he

Res R: ... would prefer my dog [because he provides] the personal touch - it breaks down barriers.

Current $\mathrm{O}$ and $\mathrm{M}$ training was generally well praised, but there were suggestions that instructors needed to appreciate that different people require different things, that the time lag between losing sight and $\mathrm{O}$ and $\mathrm{M}$ training needs to be reduced, and new technologies need to be incorporated. As Res H states:

Res H: Even though I can negotiate things, I tend to do it my way. $O$ and $M$ instructors need to recognise this, rather than just sticking to the text book way. For instance, in using the cane, I know how to correct my step if I get out of step with the cane. Also, I would keep more to the inside 
of the kerb, towards the wall. When using a sighted guide I would rather hold their hand than their elbow. People aren't aware that there are so many different ways to do it. What ever works for you and you are comfortable with is the best to use.

\section{Conclusions}

In this paper the geographies of people with visual impairments have been explored through an examination of qualitative data collected via structured open-ended interviews. The transcripts reveal that people with severe visual impairments do live within transformed spaces; urban environments that are more difficult to traverse through than for sighted individuals. The problems of unsighted navigation were revealed to depend upon both 'self-produced' and 'situational' confusion. In the first instance, spatial confusion was introduced due to a misprocessing of spatial knowledge or through incomplete spatial knowledge. It was suggested that the best way to tackle 'self-produced' confusion was through improved navigational aids that provided visually impaired people detailed spatial information concerning specific routes/areas. In the second instance, spatial confusion was introduced through specific permanent and temporary features and occurrences in the environment including street furniture, roadworks, and vehicles parked on the pavement, which all disrupt the paths taken by visually impaired people and require adjusting spatial actions. It was suggested that the best way to tackle 'situational' confusion was through simple, low cost alterations, such as minimising the amount of street furniture, painting the edges of curbs and steps, introducing tactile pavements at key locations, and altering the position and size of signs. In addition, alterations need to be standardised across environments. As such, the interviews indicated that the introduction of improved navigation aids and improved environments will reduce levels of spatial confusion, reduce fear and anxiety and increase confidence, and will hopefully lead to greater independent travel along more routes within an urban area; that the transformed geographies of blindness will be negated.

Given that the data this paper details have been derived from short, thirty minute interviews consisting of structured, open-ended questions, designed to provide contextual information for stages two and three of the study, there is a need to extend the analysis to examine further the spatial lives of visually impaired people in a more systematic manner. This initial analysis highlights that the quality of urban living experienced by visually impaired people is far from its potential standard, and a number of issues clearly need further exploration. Other future research should focus upon methods to make urban environments more inclusive - designing, testing and implementing specific changes that might reduce the number of problems encountered by visually impaired people and could aid independent travel - and upon the testing of current navigation technologies and the development of effective and inexpensive new aids.

\section{Acknowledgement}

This research is the first phase of a larger project funded by NSF grant 'Understanding geographic space without the use of vision', (SBR9514907). The authors wish to express their gratitude to all the participants who took part in the study.

\section{References}

BRAMBRING, M. (1982) Language and geographic orientation for the blind, In:Jarvella, R.J. and Klein, W. (eds) Speech, Place and Action: Studies in Deixis and Related Topics. Chichester: John Wiley, 203-218.

BRUCE, I., McKENNELL, A. and WALKER, E. (1991) Blind and Partially Sighted Adults in Britain: The RNIB Survey, Vol. 1. London: HMSO.

BUTLER, R. and BOWLBY, S. (1997) Bodies and spaces: an exploration of disabled people's experiences of public space, Society and Space, 15, 411-433.

CLARK-CARTER, D.D., HEYES, A.D. and HOWARTH, C.I. (1986) The efficiency and walking speed of visually impaired pedestrians, Ergonomics, 29, 779-789. 
COOK, I. (1991) Drowning in See World? Critical Ethnographies of Blindness. Unpublished Master's Thesis, Department of Geography, University of Kentucky.

FOULKE, E. (1983) Spatial ability and the limitations of perceptual systems, In: Pick, H.L. and Acredolo, A.J. (eds) Spatial Orientation: Theory, Research and Application, New York: Plenum Press, 125-141.

GOLLEDGE, R.G. (1991) Tactual strip maps as navigation aids, Journal of Visual Impairment and Blindness, Sept, 296301.

GOLLEDGE, R.G. (1993) Geography and the disabled: a survey with special reference to vision impaired and blind populations, Transactions of the Institute of British Geographers, 18, 63-85.

GOLLEDGE, R.G., KLATZKY, R.L. and LOOMIS, J.M. (1996) Cognitive mapping and wayfinding by adults without vision, In: Portugali, J. (ed.) The Construction of Cognitive Maps. Dordrecht: Kluwer, 215-246.

GOLLEDGE, R.G., KLATZKY, R.L., LOOMIS, J.M., SPEIGLE, J., and TIETZ, J. (in press) A Geographic Information System for a GPS based Personal Guidance System. International Journal of Geographical Information Systems.

GOlledGe, R.G., MARSTON, J.R., COSTANZO, C.M. (1998) Assistive devices and services for the disabled. Final Report. February. University of California Achievement Field Station PATH Division Grant \#MOU276.

HALL, E. (1995) Contested (Dis)Abled identities in the urban labour market. Proceedings of the Tenth Urban Change and Conflict Conference. London: Royal Holloway, 1-26.

JACOBSON, R.D. (in press) Cognitive mapping without sight: Four studies of spatial learning, Journal of Environmental Psychology.

JACOBSON, R.D. and KITCHIN, R.M. (in press) Geographical information systems and people with visual impairments or blindness: Exploring the potential to education, orientation and navigation, Transactions in GIS.

KITCHIN, R.M., BLADES, M. and GOLLEDGE, R.G. (1997) Understanding spatial concepts at the geographic scale without the use of vision, Progress in Human Geography, 21, 225-242.

KITCHIN, R.M. and TATE, N. (forthcoming) Conducting Research in Human Geography. Harlow: Longman.

KLATZKY, R.L., LOOMIS, J.M., GOLLEDGE, R.G., CICINELLI, J., DOHERTY, S., and PELLEGRINO, J. (1990) Acquisition of route and survey knowledge in the absence of vision, Journal of Motor Behavior, 22, 19-43.

LOOMIS, J., KLATZKY, R.L., GOLLEDGE, R.G., CICINELLI, J.G., PELLEGRINO, J.W. and FRY, P.A. (1993) Nonvisual navigation by blind and sighted: Assessment of path integration ability, Journal of Experimental Psychology, General 122, 73-91.

MORRONGIELLO, B.A., TIMNEY, B., HUMPHREY, G.K., ANDERSON, S., and SKORY, C. (1995) Spatial Knowledge in Blind and Sighted Children, Journal of Experimental Child Psychology, 59, 211-225 .

PARK, D., RADFORD, J. and VICKERS, M. (1988) Disability studies in human geography, Progress in Human Geography, 22, 208-233.

PASSINI, R., PROULX, G. and RAINVILLE, C. (1990) The spatio-cognitive abilities of the visually impaired population, Environment and Behavior, 22, 91-118.

PATTON, M. (1990) Qualitative Evaluation and Research Methods, ${ }^{\text {nd }}$ Edition. London: Sage.

SHOLL, M.J. (1996) From visual information to cognitive maps, In: J. Portugali (ed.) The Construction of Cognitive Maps. Dordrecht: Kluwer, 157-186.

UNGAR, S., BLADES, M., SPENCER, C. and MORSLEY, K. (1994) Can young visually impaired children use maps to estimate directions in the environment?, Journal of Visual Impairment and Blindness, 88, 221-233. 